\title{
Missing North Atlantic cyclonic precipitation in ECMWF numerical weather prediction and ERA-40 data detected through the satellite climatology HOAPS II
}

\author{
Christian-PhilipP KLEPP, StePhan BAKAN and HARTMUt GRASSL
}

\author{
Max-Planck Institut für Meteorologie and Meteorologisches Institut, Universität Hamburg, Germany
}

(Manuscript received May 10, 2005; in revised form July 11, 2005; accepted July 11, 2005)

\begin{abstract}
Intense precipitation associated with wintertime North Atlantic cyclones occurs not only in connection with frontal zones but also, and often mainly, embedded in strong cold air outbreaks to the west of mature cold fronts. Coherent structures of cloud clusters organized in mesoscale postfrontal low-pressure systems are frequently found in satellite data. Such postfrontal lows (PFL) can develop into severe weather events within few hours and can even reach Europe causing intense convective rainfall and gale force winds. Despite predicting the major storm systems numerical weather prediction (NWP) additionally needs to account for PFLs due to their frequent occurrence connected with high impact weather. But while the major cyclone systems are mostly well predicted, the forecast of PFLs remains poor. Using North Atlantic weather observations from the 1997 Fronts and Atlantic Storm Track Experiment (FASTEX) along with the standard voluntary observing ship (VOS) data led to a high quality validation data set for this usually data sparse region. For individual case studies of FASTEX cyclones with mesoscale PFLs investigations were carried out using the well calibrated precipitation estimates from HOAPS (Hamburg Ocean Atmosphere Parameters and fluxes from satellite data) compared to the NWP model output of the ECMWF (European Centre for Medium-Range Weather Forecasts). Preceding studies showed that the HOAPS precipitation structure and intensities are in good agreement with the VOS observations for all observed precipitation types within the cyclones, including PFLs. To assure that the results found in the 1997 data are still valid in the more recent ECMWF model system, a PFL rainfall comparison is carried out using HOAPS and ERA-40 (ECMWF Re-Analysis) data for the winter of 2001 and 2002. The results indicate that the ECMWF model is mostly well reproducing precipitation structures and intensities associated with frontal systems as observed in the VOS and HOAPS data, whereas PFL precipitation is mostly missing. Further investigations within the regions of PFL point out that the VOS observed surface pressure is systematically lower than reproduced in the models. This leads to the conclusion that the missing PFL precipitation in ECMWF may be primarily due to the absence of the corresponding mesoscale low-pressure system.
\end{abstract}

\begin{abstract}
Zusammenfassung
Intensive Niederschläge in nordatlantischen Tiefdruckgebieten existieren, vor allem im Winterhalbjahr, nicht nur in den Frontalzonen sondern auch innerhalb der Kaltluftausbrüche auf der Rückseite von Kaltfronten. Hier entstehen häufig stark konvektiv geprägte mesoskalige Tiefdruckgebiete (PFL) die innerhalb weniger Stunden zu intensiven Wettererscheinungen heranwachsen können. Diese erreichen zum Teil auch den europäischen Kontinent und können dort zu Orkanen mit Starkregen führen. Die Aufgabe der numerischen Wettervorhersage ist somit neben der Erfassung der großskaligen Tiefdruckgebiete zunehmend auch diese kleinräumigen wetterintensiven Störungen zu erfassen und korrekt vorherzusagen. Während ersteres inzwischen zufriedenstellend gelingt, ist die Modellerfassung und Vorhersage von PFLs nach wie vor unzureichend. Ein umfangreicher Datensatz von Schiffswetterbeobachtungen (VOS) zur Validierung von Niederschlägen wurde während der FASTEX Feldkampagne im Februar 1997 von Forschungs- und Handelsschiffen gewonnen. Hierbei standen vor allem auch Daten in Regionen zur Verfügung, die einerseits sonst nur selten von Schiffen befahren werden und anderseits häufig PFLs aufweisen. 10 PFL Ereignisse konnten in diesem Zeitraum untersucht und mit Daten des EZMW (Europäisches Zentrum für Mittelfristvorhersage) und der Satellitenklimatologie HOAPS (Hamburg Ocean Atmosphere Parameters and fluxes from Satellite data) verglichen werden. Vorausgehende Studien belegen, dass die Niederschlagsmuster und -Intensitäten der HOAPS Klimatologie in guter Übereinstimmung mit den beobachteten Niederschlägen der VOS Daten sind. Zusätzlich wurden EZMW ERA-40 Reanalysedaten für den Winter 2001/2002 herangezogen um zu prüfen, ob das neuere Modellsystem, respektive aktuellere Fälle, dasselbe Verhalten zeigen wie die untersuchten Fälle aus 1997. Die Ergebnisse zeigen, dass das EZMW Modell frontale Niederschlagsstrukturen und -Intensitäten, in Übereinstimmung mit den VOS und HOAPS Daten, zumeist zuverlässig erfasst. Dagegen fehlen die beobachteten mesoskaligen PFL Niederschläge zumeist gänzlich. Detaillierte Untersuchungen in den PFLs zeigen, dass der beobachtete VOS Bodendruck systematisch erheblich niedriger ist als vom Model repräsentiert. Dies führt zu der Folgerung, dass der fehlende Modellniederschlag in den PFLs primär eine Folge des zu schwach entwickelten Modelltiefdrucks sein kann.
\end{abstract}

${ }^{*}$ Corresponding author: Christian-Ph. Klepp, Meteorologisches Institut der Universität Hamburg, Max-Planck Institut für Meteorologie, Bundesstraße 55, 20146 Hamburg, Germany, e-mail: klepp@dkrz.de 


\section{Introduction}

The atmospheric water cycle is a key part of the climate system. However, the interactions of several components of the water cycle are still not understood sufficiently. In particular, the description of rainfall processes due to the extremely localized and intermittent nature of rain processes remains one of the key deficiencies of climate simulations (IPCC, 2001). The atmospheric part of the water cycle over the mid-latitude oceans is primarily driven by water exchange in cyclones. The North Atlantic is one of the key regions in global climate coupling, as the global oceanic conveyor belt system is triggered within this region. This system is inter alia sensitive to the amount of precipitation entering the ocean. In addition, Earth's largest horizontal SST gradients exist in the western North Atlantic that result in large air/sea temperature differences causing intense convection and rainfall, especially off the east coast of the United States and off Newfoundland. It is therefore of major importance to understand all relevant processes within the cyclones that contribute major amounts of precipitation and drive the freshwater flux. This paper will focus on a mesoscale postfrontal low (PFL) precipitation type that is vastly underestimated in both the satellite and model community. North Atlantic PFL precipitation is a dominant contributor to the water cycle (KLEPP et al., 2003). Especially in wintertime, this precipitation type can be observed nearly daily. It emerges as one of the dominant North Atlantic precipitation features in the 15 year HOAPS satellite climatology (KLEPP et al., 2005). This leads to the conclusion that improvements of skillful weather prediction in numerical weather prediction (NWP) models remains one of the important scientific and societal challenges.

PFLs are associated with intensively precipitating convective mesoscale cloud clusters. A mature North Atlantic cyclone is needed to generate a strong cold air outbreak west to the postfrontal subsidence of the cold front. PFLs only form within such cold air outbreaks from continental U.S. or Canada over the area of the strongest horizontal SST gradients. This limits the area of occurrence for strong PFLs to the coast off New Foundland and the Gulfstream waters off continental U.S. PFLs can reach the coasts of Europe causing intense convective precipitation and gale force winds (WILLIAMS, 2000). Usually they are transported within the west wind drift, showing a significant weakening. The observed intense local surface pressure drops in the surrounding high pressure of the cold air outbreaks indicate that PFLs correspond to mesoscale low pressure systems. They can rapidly develop out of tiltback occlusions. In these cases, the cloud and precipitation structures exhibit no longer a connection to the mature cyclone. They also develop in regions of strong conver- gence in the surface wind field, where the cloud streets narrow and grow into convective systems. Infrared and visible satellite images show that the convection remains relatively shallow and seldom exceeds 3 to $5 \mathrm{~km}$ in height. There is first evidence that PFLs can rotate anticlockwise as VOS showed a cyclonic wind shift up to $50^{\circ}$. Scatterometer data from the NSCAT satellite also show a cyclonic shift in the wind field, but it is not investigated yet, if the resolution really can support these first results. Further investigations with high resolution ERS satellite data are envisaged. Although the cloud structures often resemble those of polar lows, there is a significant difference in the amount of rainfall in PFLs up to factor of 10 .

High quality water cycle parameter data sets are therefore urgently needed. Satellites are the only source to supply such sets with the required spatial and temporal coverage as the sparse in-situ measurements are not sufficient for homogeneous fields of consistent quality. Therefore, microwave satellite data from the Special Sensor Microwave/Imager (SSM/I) onboard the Defense Meteorological Satellite Program (DMSP) platforms, have become the major source of information for precipitation rates and precipitation patterns together with other climatically relevant parameters on a global ocean scale (WENTZ, 1991). However, remote sensing data provide only an indirect measure, i.e. brightness temperatures in several spectral channels. The required quantity - in our case the rain rate at the ocean surface - is derived through the application of appropriate algorithms. Although these are usually derived from basic physical principles, they require independent in-situ surface observations for validation.

Previous extensive studies, such as the algorithm intercomparison project (AIP) and precipitation intercomparison project (PIP) by EBERT and MANTON, 1996 and SMITH et al., 1998 have been comparing SSM/I rainfall algorithms on either a global scale for monthly means or detailed intercomparisons in the tropics with ground based radar observations as a ground truth. The overall results were, that most investigated rainfall algorithms compare quite well for monthly means on global scale but can vary significantly on a regional scale, especially when applied in case studies.

KLEPP et al. (2003) compared six state of the art algorithms from the AIP and PIP studies on a mid-latitude regional scale for application in instantaneous North Atlantic cyclone case studies. The aim of that study was to identify similarities and differences of these algorithms for retrieving rainfall for individual North Atlantic cyclones. The results clearly pointed out the need for independent ground truth data such as the present weather observations from VOS. These observations are collected every six hours on a routine basis and include rainfall observations together with several other 
directly measured parameters like the mean sea level pressure (MSLP). The time period chosen was January and February 1997 in order to coincide with the Fronts and Atlantic Storm Track Experiment (FASTEX, JOLY et al., 1997). The operational observations were strongly increased during this period with additional observations from research vessels operating for FASTEX in the usually very data sparse regions of the northern North Atlantic. This gave the opportunity for validating the passive microwave remote sensing rainfall algorithms utilizing all available DMSP satellites. This is done using the multi-satellite technique (KLEPP et al., 2003) that blends information of up to three SSM/I sensors into a combined product. This allows a complete coverage of the North Atlantic assuring that the investigated cyclones are completely covered.

It could be shown that the remote sensing rainfall algorithm of BAUER and SCHLÜSSEL (1993), called SBSA in KLEPP et al., (2003) and used in HOAPS (Hamburg Ocean Atmosphere Parameters and Fluxes from Satellite data) emerges as the first choice for North Atlantic precipitation fields in cold and warm fronts, post frontal lows (PFL) and areas of cyclogenesis. The HOAPS climatology contains global fields of precipitation, turbulent heat fluxes and the freshwater flux mainly derived from SSM/I satellite data over the ice free oceans since 1987 (GRASSL et al., 2000; JOST, 2000; JosT et al., 2002; KLEPP et al., 2005).

The main goal of the present study is to investigate the ability of the ECMWF model to reproduce the North Atlantic rainfall patterns and intensities in cyclonic rainfall regions provided by the HOAPS satellite observations. KLEPP et al., 2003 showed for a sample case that especially the PFL precipitation behind the cold front, organized in a post frontal low pressure system, contributes up to $60 \%$ instantaneously and up to $25 \%$ to the total amount of rainfall of a typical wintertime cyclone. Such freshwater inputs of about $1 \mathrm{~Sv}\left(10^{6} \mathrm{~m}^{3} / \mathrm{s}\right)$ into the ocean are essential for the water cycle over the North Atlantic and a proper model representation of such events is therefore of major importance for a correct representation of the freshwater flux and hence the salinity of the surface water body. Such PFLs to the west of mature cold fronts can be found in the HOAPS data base nearly every day in wintertime, whenever a mature cyclone system leads to a cold air outflow from Canada (KLEPP and BAKAN, 2000; KLEPP, 2001; KLEPP et al., 2003).

In these cases atmospheric disturbances rapidly develop into PFLs causing high-impact weather (HIW) regimes that may have a potential risk for shipping. Further development may cause landfall of violent storms in Western Europe in conjunction with heavy rainfall. The PFL of the cyclone from 17 February 1997 developed into a mesoscale comma cloud to the west of the cold front of the mature cyclone "Caroline". The comma cloud reached Ireland and Great Britain on 18 February 1997 causing HIW with rainfall up to $16 \mathrm{~mm} \mathrm{~h}^{-1}$ and gale force winds (WILLIAMS, 2000).

Therefore the HOAPS precipitation fields for the same ten wintertime cyclone case studies as used in KLEPP et al. (2003) as well as VOS data for sea surface temperature (SST), air temperature and surface pressure were compared to the model output of the operational NWP model of ECMWF. The cyclone "Caroline" from 17 February 1997 and its corresponding PFL, which is even not among the strongest of the ten events studied, is chosen to represent the intercomparison study.

After a description of the data sources in Section 2 and a review of preceding studies in Section 3 the major results of this study are presented in Section 4 while Section 5 contains the discussion of the findings as well as conclusions.

\section{Data sources}

The precipitation fields of North Atlantic cyclones used in this study originate from the HOAPS data base using all available passive microwave radiometers, in-situ VOS data and NWP model output from the ECMWF forecast mode (FG-First Guess), its analysis version (AN-Analysis) and the 40 years ECMWF Reanalysis (ERA-40).

The major investigated period was chosen to coincide with the FASTEX field experiment in January and February 1997, during which the number of high quality shipboard weather observations in the target area was massively increased including observations every three hours. The aim of FASTEX was to study the life cycle of individual cyclones and their impact on the European coasts (JOLY et al., 1997). Within the FASTEX period we used case studies from 23 and 24 January 1997 together with 09, 14, 17, 19, 24 February 1997. Results are primarily shown for the case study from 17 February 1997. Additionally we used a case study from 14 March 1993. A detailed analysis of 159 North Atlantic cyclone fronts detected in November 1992 were used to compare the horizontal displacements and frontal length differences between the HOAPS and ECMWF data sets. To further proof, if the results obtained for the 1997 model system of ECMWF are still valid for more recent model versions, we added a rainfall comparison between HOAPS and ERA-40 data for 90 PFL cases in December 2001, January and February 2002. The case study from 17 February 1997 is also repeated using ERA-40 data. The results are given in Section 4d.

The SSM/I brightness temperature data (WENTZ, 1991) as measured by three DMSP satellites (F10, F11 and F13) were obtained from NOAA NESDIS (National Environmental Satellite Data and Information Service) and were subjected to the rain rate algorithm of BAUER 


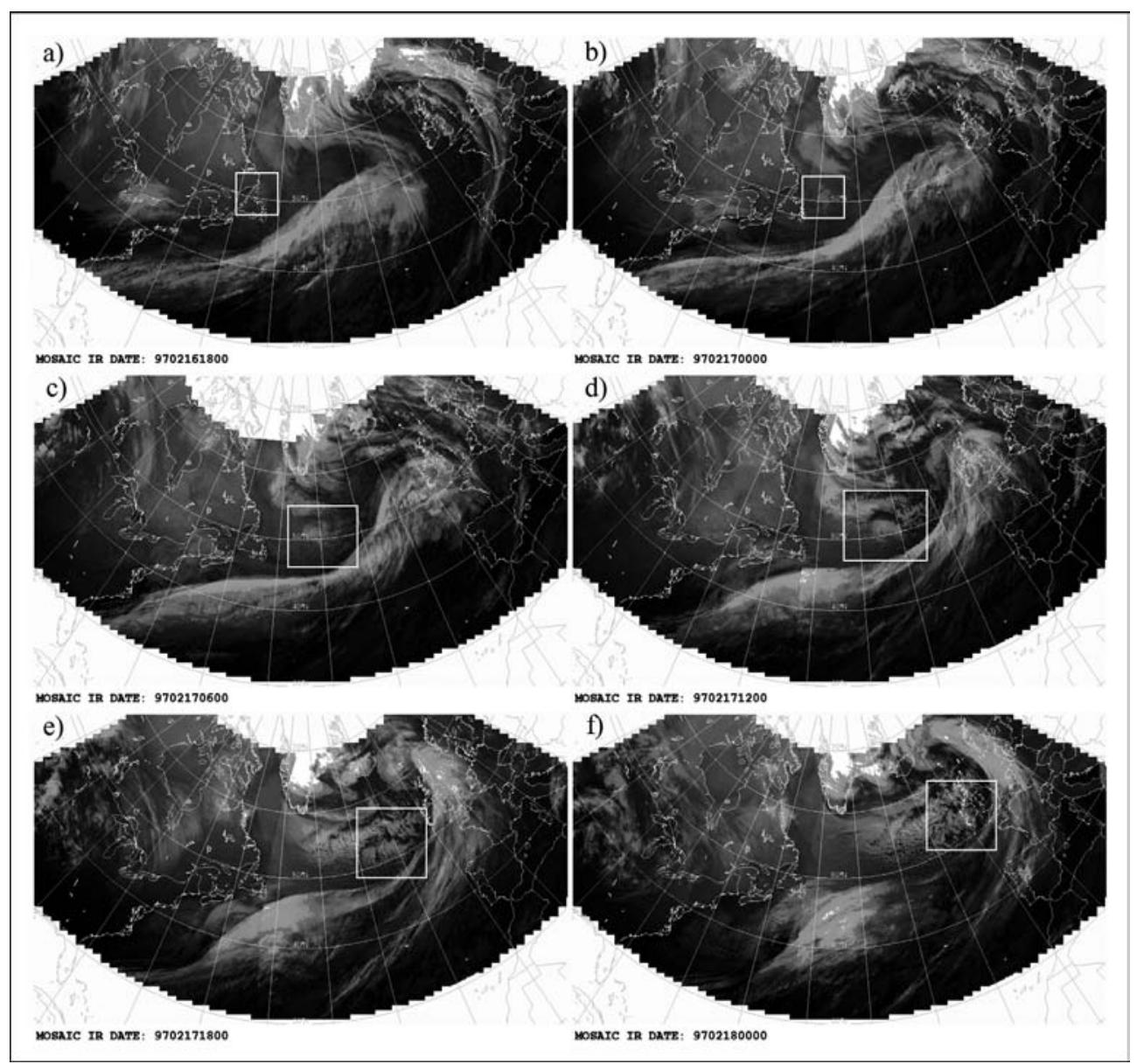

Figure 1: The development of the PFL from 17 February 1997 (white boxes) as seen by a composite of infrared sensors (GOES-E, NOAA AVHRR and METEOSAT) from 16 February 1997, 18 UTC to 18 February 1997, 00 UTC, that were composed for the FASTEX period. Data source: www.cnrm.meteo.fr/dbfastex/.

and SCHLÜSSEL (1993) that is used in the HOAPS data base. The HOAPS dataset contains global fields of precipitation, turbulent heat fluxes, net freshwater flux, and all the basic sea surface state variables needed for the derivation of the fluxes since 1987. Except for the NOAA Pathfinder SST dataset (SUSSKIND et al., 1997), all variables are derived from SSM/I satellite data over the ice free ocean using multi-satellite averages with proper inter-satellite calibration (www.hoaps.org; GrASSL et al., 2000; JoST et al., 2002; KLEPP et al., 2005). For the present study the scan based version of the dataset was used.

The VOS data, containing measured values of meteorological variables and present weather type, is provided by the European Centre for Medium-Range Weather Forecasts (ECMWF), stored in the original raw data format. The present weather type (in coded format) is of major importance for validating satellite rainfall estimates due to the sparse observations over the oceans. We also use our method converting this code into precipitation rates in $\mathrm{mm} / \mathrm{h}$ (KLEPP et al., 2003). Additionally, the VOS parameters air temperature, SST, wind speed, wind direction, 3-hourly pressure trend and past weather as well as cloud types were compared to modeled and satellite derived fields.

ECMWF began operational activities in 1979. It has developed one of the major NWP models for global applications. The model version used here (T213L31) has a spatial resolution of $0.562^{\circ}$ with 31 vertical levels from the surface to a height of $30 \mathrm{~km}$. A more detailed model description is given in the ECMWF (1994) user guide manuals. In this study, ECMWF surface data are used and compared to HOAPS. Mainly, the six hour forecast from the medium range data (First Guess - FG) of precipitation are used. This parameter is a composite of the stratiform (large-scale) and convective precipitation stored in the model codes 142 and 143. In the mid-latitudes the model precipitation is to a large extent dominated by the stratiform component. Additionally, the mean sea level pressure is used from this FG and the analysis (AN) data set and is validated with in-situ data from VOS. The analysis is only made for parameters that are directly measured, such as MSLP but not for precipitation. 


\section{Quality of satellite derived precipitation fields}

Comparing cyclonic rainfall patterns, their locations and intensities using different data sources such as remote sensing, model output and in-situ observations usually results in a large range of values that are often inconsistent with each other. Because of the importance of rainfall with respect to the global water cycle, there is a strong need to identify the best estimate. KLEPP et al. (2003) did this in an extensive comparison of six well known remote sensing precipitation algorithms with insitu VOS data including additional ship observations from the FASTEX campaign in January and February 1997. The remote sensing data were based on the microwave sensors SSM/I on the Defense Meteorological Satellite Program (DMSP) orbiters F10, F11 and F13 using a multi-satellite method. Single satellite orbits usually result in large spatial and temporal data gaps that considerably hamper the investigation of individual rainfall events. The combination of data from three satellites led to a complete data coverage of the North Atlantic twice daily using the descending orbits between 06 and 12 UTC and the ascending orbits between 21 and 00 UTC. The F13 satellite was used as a reference because its North Atlantic overpasses nearly equal the synoptic routine observations at 06 UTC and 18 UTC.

Ten case studies in January and February 1997 were selected that all contained mature cyclones and corresponding PFL precipitation. The SSM/I precipitation fields were derived using the SSM/I BAUER and SCHLÜSSEL (1993) algorithm within the HOAPS database, the scattering based Ferraro algorithm (FERRARO and MARKS, 1995), the precipitation algorithm from WENTZ (1997) as well as the three following algorithms from the Global Precipitation Climatology Project (GPCP): The scan based GPCP Goddard Profiling algorithm (GPROF) by KUMMEROW et al. (2001) in versions 4.0 and 6.0, and the one-degree daily GPCP 1DD combined product (HuFFMAN et al., 1997). Additionally, infrared Advanced Very High Resolution Radiometer (AVHRR) data were used to identify the corresponding cloud fields.

Despite a wide spread of rainfall intensity up to $5 \mathrm{~mm} / \mathrm{h}$ all tested remote sensing algorithms agreed fairly well on rainfall patterns along fronts and in the cyclogenesis stages. In contrast, large discrepancies exist in the estimation of rainfall in PFLs in all cases studied, only the HOAPS data showed significant amounts of rainfall whereas nearly all other algorithms failed to estimate even any precipitation at all.

Therefore, further investigations had to clarify the existence of the PFL rainfall seen in the HOAPS data only. Ship observations were used to prove whether FASTEX scientists and commercial ship reports ob- served the PFL rainfall. It is remarkable that 40 VOS rainfall observation existed within the PFLs from which 17 were coded like "violent rain showers" or "thunderstorm with hail" and nearly all other reported convective types of precipitation. Therefore our confidence in the HOAPS precipitation patterns increased considerably, due to the fact that all other satellite algorithms tested did not detect precipitation in PFLs. Additionally, all rain-free observations also fitted the results of the HOAPS data. That the HOAPS rainfall algorithm is able to outperform other passive microwave rainfall algorithms in the regions of PFL is due to the algorithm structure. PFLs are always represented as a local maximum in the brightness temperatures of all seven SSM/I channels. Due to the extremely cold atmosphere during the cold air outbreaks these local maxima are mostly below the brightness temperature thresholds of other algorithms resulting in exclusion of these cases to give rainfall. In contrast, the HOAPS algorithm is not operating on thresholds in the brightness temperature but on thresholds in cloud liquid water. Heavy precipitation within PFLs results, although the atmosphere during cold air outbreaks is usually relatively dry. The moisture is brought into the atmosphere when the extremely cold air is advected over the warm Gulfstream waters. The largest horizontal SST gradients on earth are found off the coast of Newfoundland. The air/sea temperature differences are found to exceed $17 \mathrm{~K}$ in these cases. The resulting very strong sensible and latent heat fluxes into the atmosphere can cause the rapid development of the PFLs.

The next validation step was to convert the VOS rainfall weather codes into rainfall rates in $\mathrm{mm} / \mathrm{h}$ to verify the rainfall intensity for all tested algorithms and cyclone regions. Seven rainfall classes were defined covering the range of VOS codes (KLEPP et al., 2003). The mean passive microwave rainfall values of all used remote sensing data except HOAPS and the PFL area were used to calibrate seven rainfall classes from light drizzle to violent rain showers of each rainfall regime, i.e. cold and warm fronts and cyclogenesis. To remain independent, thereafter the scheme was applied to the HOAPS data and for the PFL regions as well. Again it could be shown that the HOAPS data are in compliance with the VOS rainfall intensities reported for the PFL regions.

\section{Results}

\subsection{Rainfall intercomparison study}

The region of frequent PFL occurrence off the coast of Newfoundland can be considered as a key region for the North Atlantic climate system. There, the warm waters of the Gulf stream come into contact with the polar water mass of the Labrador Sea resulting in the 
a)

b)
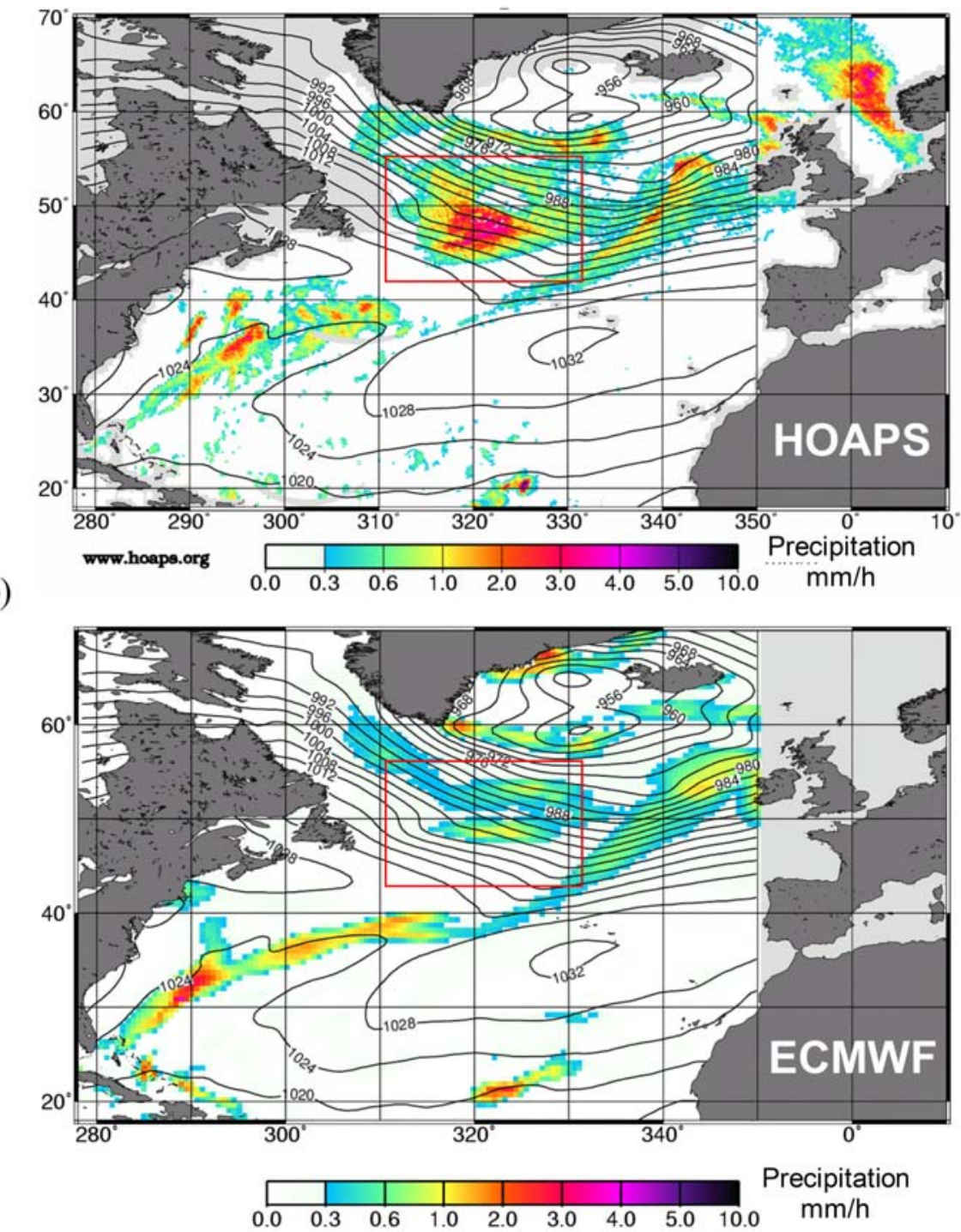

Figure 2: Precipitation rate $(\mathrm{mm} / \mathrm{h})$ comparison for a FASTEX case study cyclone dated 17 February 1997 around 09 UTC using the satellite derived database HOAPS (a) and the ECMWF model (b) showing the location of the PFL (red boxes). ECMWF data was used from 10 to $82^{\circ} \mathrm{W}$.

strongest horizontal SST gradients existing, reaching up to $15 \mathrm{~K} / 200 \mathrm{~km}$ (KLEPP et al., 2003). In wintertime, this leads to a corresponding maximum in precipitation and evaporation in this area, representing one of the dominating climatological signals in the HOAPS database over the North Atlantic. The region is an area of permanent cyclogenesis and especially the origin of frequent PFL development within the cold air west of the cold front of mature cyclones. The precipitation fields of the case study from 17 February 1997, 09 UTC are shown in Figure 2 for HOAPS (a) and ECMWF (b). The mature cyclone "Caroline" over the central North Atlantic developed from its cyclogenesis stage on 15 February 1997 into a storm system with a well developed cold front that stretches from the coast of Ireland southwest to $40^{\circ} \mathrm{N}$ and $40^{\circ} \mathrm{W}$. Figure 1 shows the develop- ment of the cyclone between 16 and 18 February 1997. The non-precipitating postfrontal subsidence area is followed by the typical cold air outbreak structure including embedded showers with weak convective precipitation. Within the cold air over the regions with strongest SST gradients, an advected small atmospheric disturbance has developed into a middle-level PFL within 12 hours (Fig. 1d) showing intense convective precipitation in the HOAPS precipitation field but not in the ECMWF model (red boxes in Figure 2). The disturbance that led to the PFL can be traced back in the composite infrared AVHRR images of Figure 1 to the 16 February 1997, 18 UTC where clouds are visible for the first time over Newfoundland marked by the white box in Figure 1a. The entire development of the PFL is shown in Figure 1a-f including the high impact weather of the comma 
Averaged PFL precipitation comparison

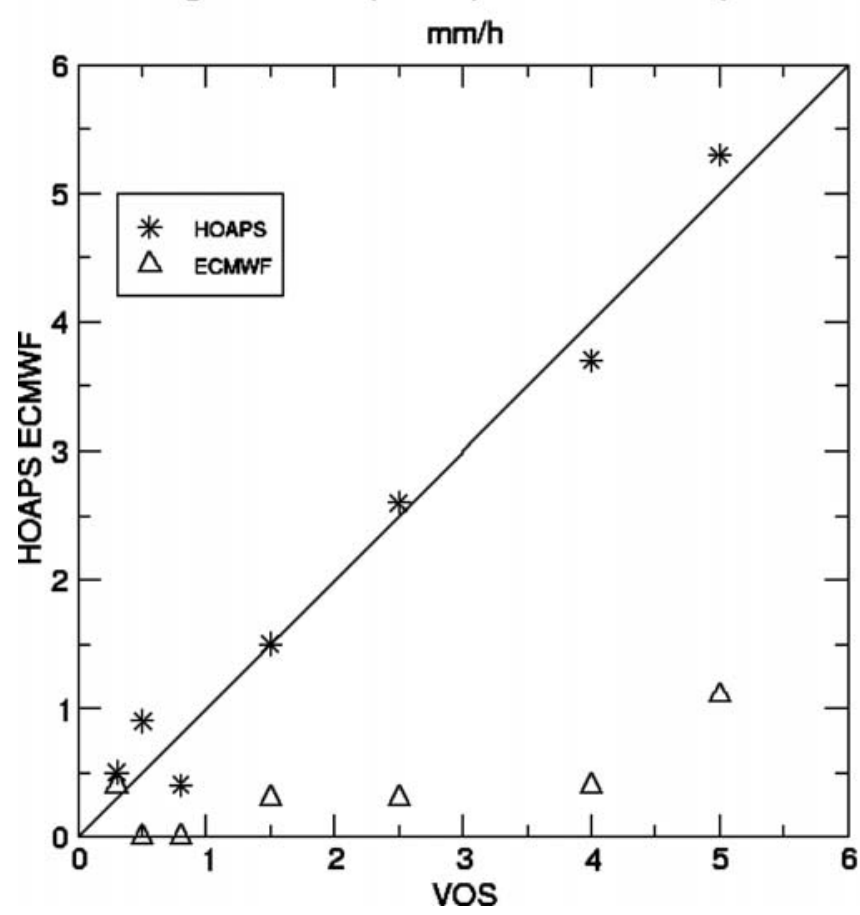

Figure 3: PFL precipitation comparison averaged over all seven rainfall classes for each data set in $\mathrm{mm} / \mathrm{h}$.

cloud stage over Great Britain on 18 February 1997, as documented by WILLIAMS (2000).

The HOAPS results from 17 February 1997 were compared to the ECMWF model output. Figure $2 \mathrm{~b}$ represents the precipitation accumulated between 06 and 12UTC in the ECMWF model. Despite the broadened and usually less intense precipitation, due to the 6hourly integration interval of the model, all frontal features of the cyclone "Caroline" agree with the results of HOAPS. Even the tropical shower system at $20^{\circ} \mathrm{N}$ and the cyclogenesis off the American coast are well represented. This is also supported by the ECMWF surface pressure field, whose isobars are included in Figure 2. The frontal structures of the ECMWF surface pressure field from 06 UTC agree in great detail with the location of the HOAPS frontal rainfall derived from satellite orbits between 06 UTC over the eastern parts and 09 UTC over the central part of the North Atlantic. This also agrees with the results of a preceding study were further 159 North Atlantic cyclone fronts in November 1992 were investigated regarding the displacement of the front and its length. Front locations and lengths represented by the HOAPS derived rainfall and precipitable water, which both are good indicators for fronts, were compared to detailed surface pressure fields of the ECMWF model to prove the consistency of both fields. 87 out of 159 fronts were easily re-identified in the ECMWF data and the horizontal displacement was within $100 \mathrm{~km}$ between both data sets. 28 fronts were

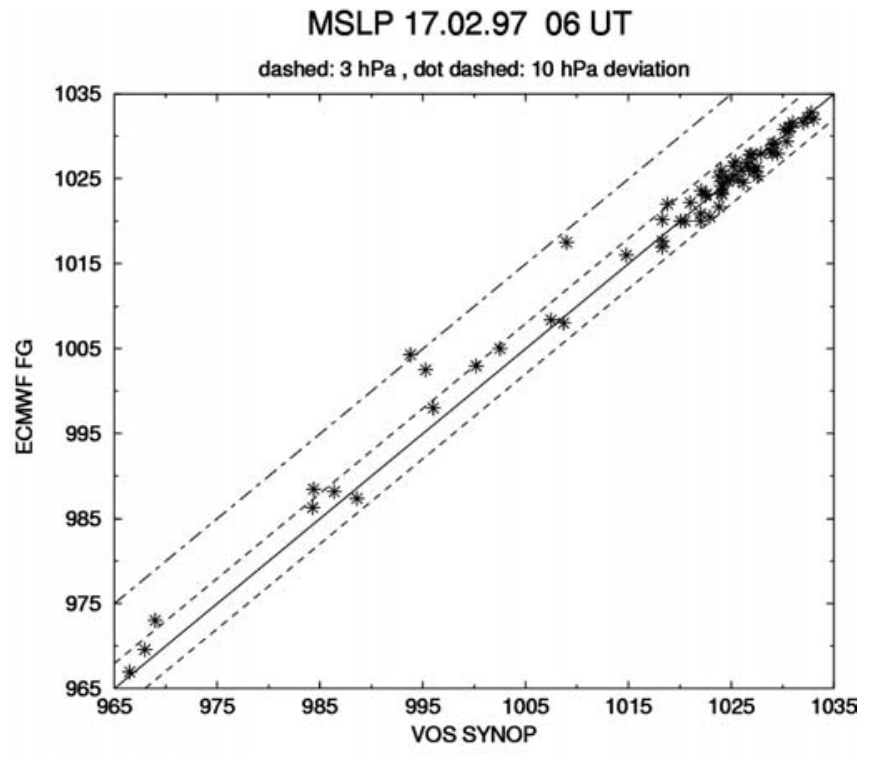

Figure 4: MSLP comparison for VOS and ECMWF FG-data for 17 February 1997, 06 UTC. The dotted line indicates the allowed 3 $\mathrm{hPa}$ between both datasets, the dot-dashed line indicates the $10 \mathrm{hPa}$ deviation.

nearly inactive or too weak to be re-identified in the ECMWF data. 19 were associated with cyclolysis or exhibited only minor amounts of precipitation in the HOAPS data. 18 fronts were located mostly over land and were therefore not detectable within HOAPS. Only few fronts were undetectable in HOAPS due to data gaps. 64 out of 159 fronts showed intensive rain and belonged to mature cyclone systems. These were additionally compared regarding the length of the fronts. 59 fronts detected in both data sets showed good agreements and the length difference was always below 150 $\mathrm{km}$. Five warm fronts were partly not detectable in HOAPS due to landfall. The detailed results are given in Table 1.

\subsection{NWP model precipitation validation using VOS data}

The procedure described in KLEPP et al. (2003) converts the rainfall observations contained in the VOS present weather codes into precipitation rates for direct comparison with the satellite rainfall rates. It is applied here to validate the VOS rainfall against the model precipitation output. Data from ten case studies, all including PFLs, were used, containing a total of 97 VOS rainfall observations. The VOS rainfall data were classified into four main cyclonic precipitation zones, i.e. warm fronts, cold fronts, PFLs and low pressure systems during early cyclogenesis. 37 observations were obtained in cold fronts, 11 in warm fronts, 40 in PFLs and 9 within cyclogenesis. The HOAPS data is used as a benchmark to verify the rainfall pattern and intensities in the ECMWF model. The procedure introduced in KLEPP et 
Table 1: Horizontal displacement and front length differences in km of 159 North Atlantic cyclone fronts in November 1992 compared between the HOAPS and ECMWF data sets.

\begin{tabular}{|c|c|c|c|c|}
\hline Horizontal shift $(\mathrm{km})$ & $\begin{array}{l}\text { Total number of } \\
\text { fronts }\end{array}$ & $\begin{array}{l}\text { Number of } \\
\text { cold fronts }\end{array}$ & Error cause & Error source \\
\hline $0-10$ & 25 & 13 & - & - \\
\hline $10-50$ & 32 & 11 & - & - \\
\hline $50-100$ & 30 & 8 & - & - \\
\hline Not recognized & 3 & 0 & HOAPS data gaps & HOAPS \\
\hline Not recognized & 3 & 0 & Cyclogenesis & ECMWF \\
\hline Not recognized & 28 & 0 & Weak fronts & ECMWF \\
\hline Not recognized & 19 & 0 & Cycloysis & HOAPS \\
\hline Not recognized & 1 & 0 & No-rain cyclogenesis & HOAPS \\
\hline Not recognized & 18 & 0 & Fronts over land & HOAPS \\
\hline Length shift (km) & $\begin{array}{l}\text { Total number of } \\
\text { fronts }\end{array}$ & $\begin{array}{l}\text { Number of } \\
\text { cold fronts }\end{array}$ & Error cause & Error source \\
\hline $0-30$ & 25 & 15 & - & - \\
\hline $30-70$ & 20 & 11 & - & - \\
\hline $70-150$ & 12 & 6 & - & - \\
\hline Not recognized & 2 & 0 & HOAPS data gaps & HOAPS \\
\hline Not recognized & 5 & 0 & Fronts over land & HOAPS \\
\hline
\end{tabular}

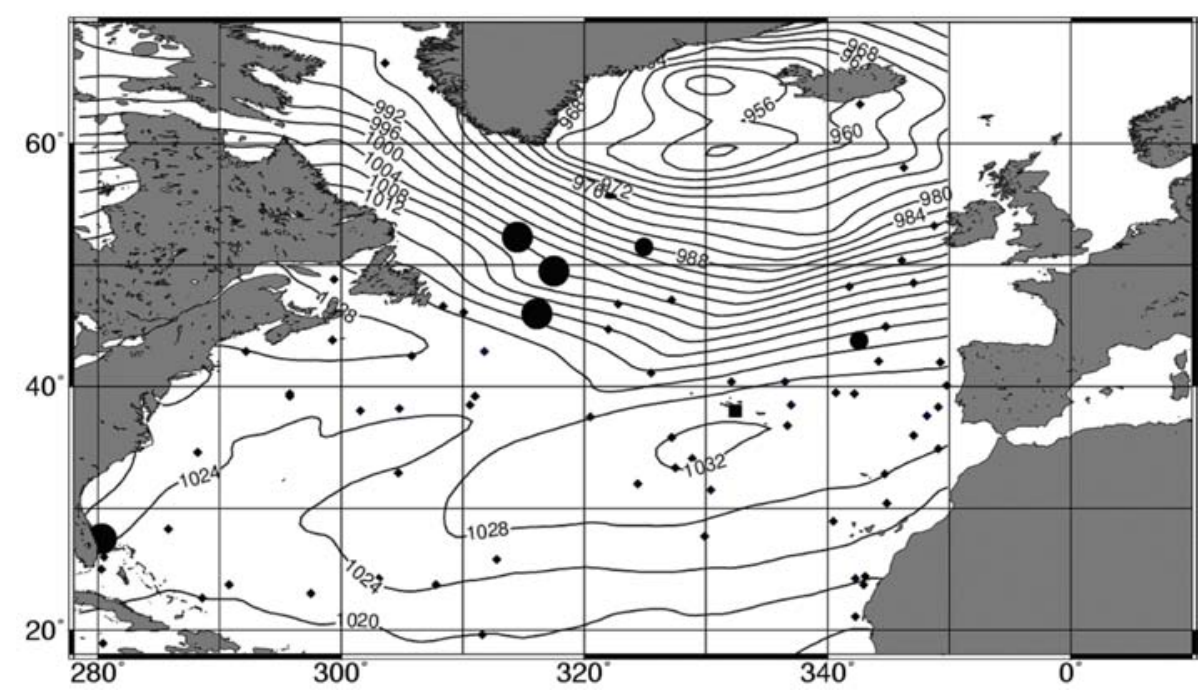

Figure 5: Comparison of the VOS MSLP data (dots and squares) and the ECMWF MSLP FG-data isobars for 17 February 1997,06 UTC. Small squares indicate MSLP differences of $\pm 3 \mathrm{hPa}$, medium size dots indicate differences up to $-5 \mathrm{hPa}$ and large dots up to $-11 \mathrm{hPa}$. The single medium sized square within the high pressure system represents a difference of $+6 \mathrm{hPa}$. ECMWF data was used from 10 to $82^{\circ} \mathrm{W}$.

al. (2003) is therefore applied to the HOAPS and the model data resulting in generally acceptable agreement between model and VOS data. For PFLs, however, only the HOAPS satellite data provide realistic results while the ECMWF model data are by far too low in most cases. The PFL rainfall underestimation in the ECMWF model can be even more clearly seen when averaging the rainfall rates within each of the seven rainfall classes that 
a)

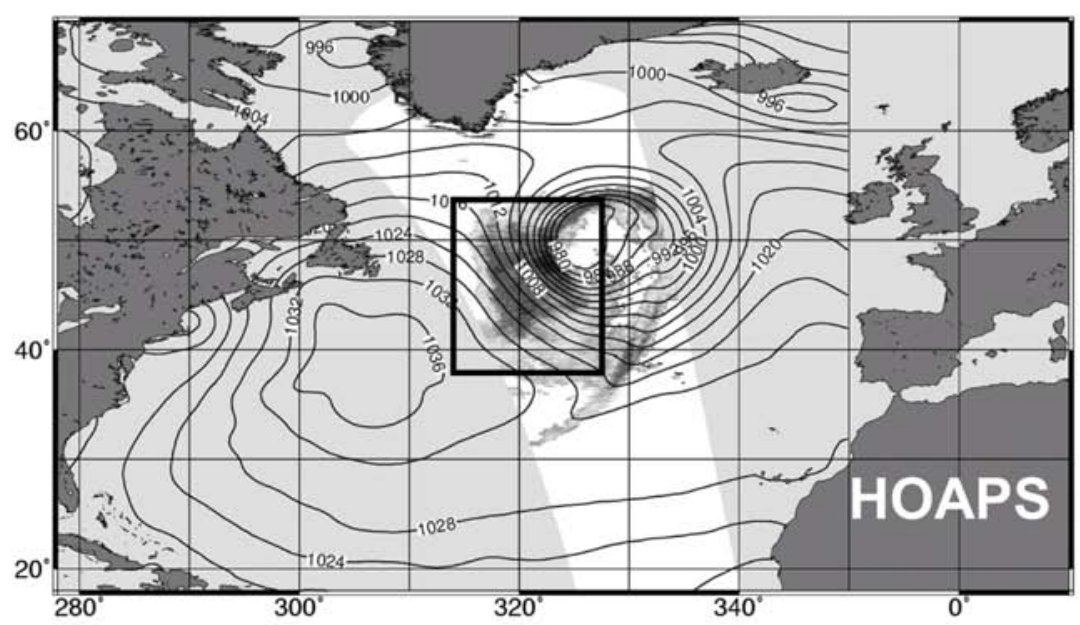

b)

Precipitation

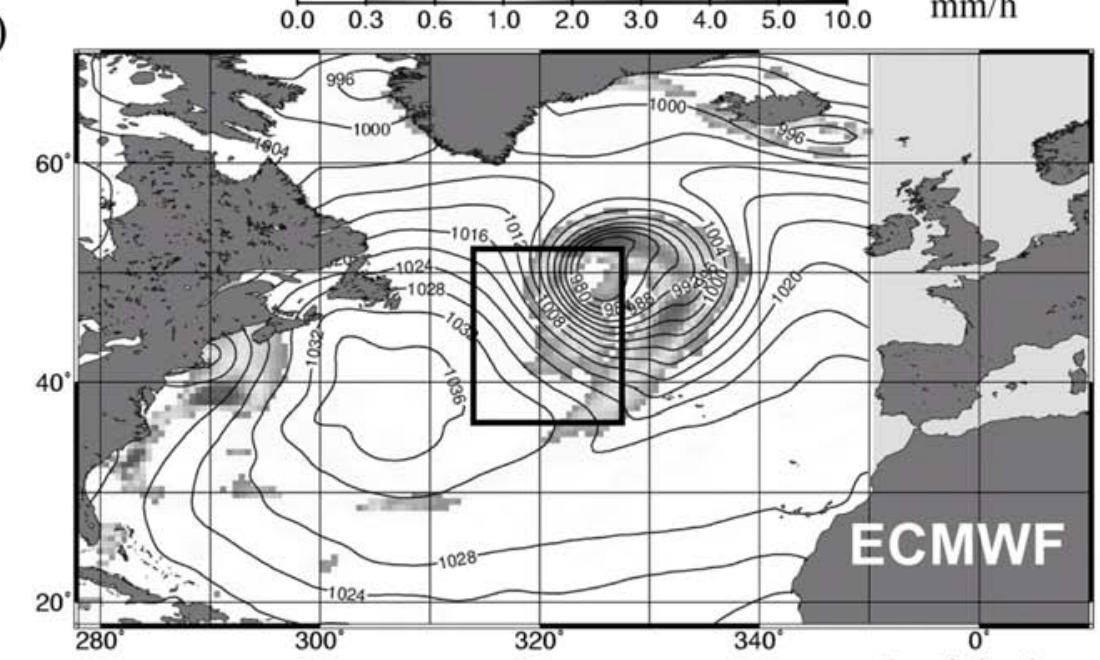

c)

Precipitation

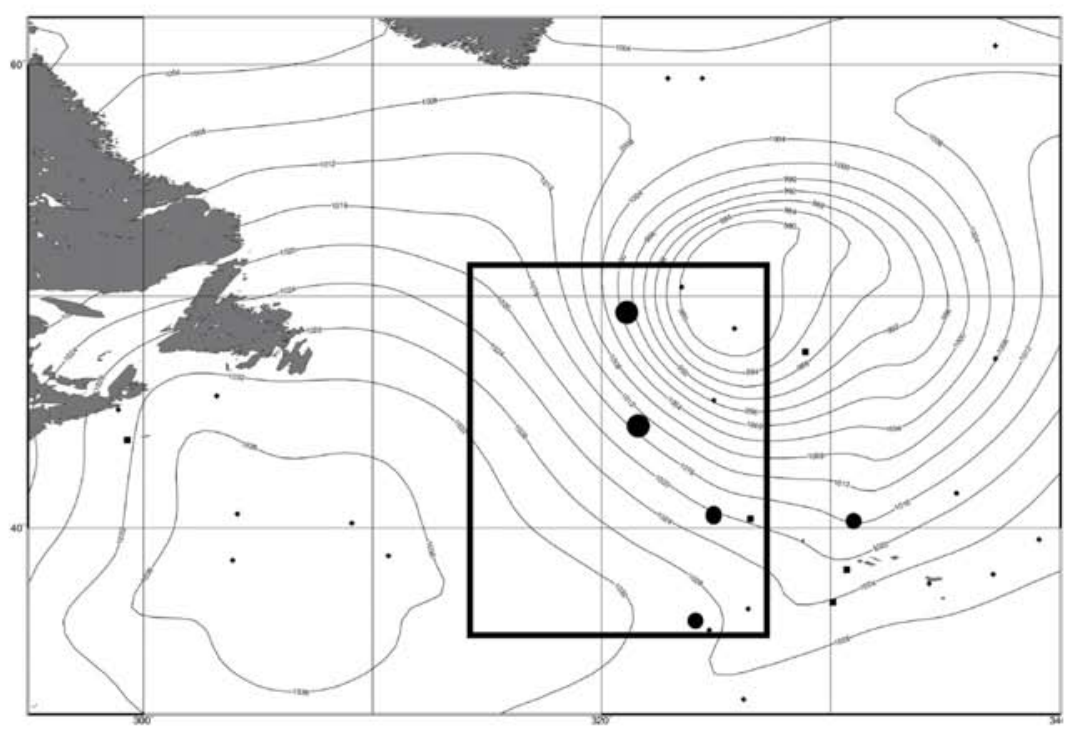

Figure 6: Precipitation rate $(\mathrm{mm} / \mathrm{h})$ comparison for a case study from 14 February 1997 using HOAPS (a) and the ECMWF model (b) showing the location of the PFL within the black boxes. A detailed surface pressure field comparison within the PFL (c) uses VOS data (dots) and ECMWF (isobars). Three medium size dots indicate pressure differences up to $-5 \mathrm{hPa}$ and two large dots up to $-16 \mathrm{hPa}$. 


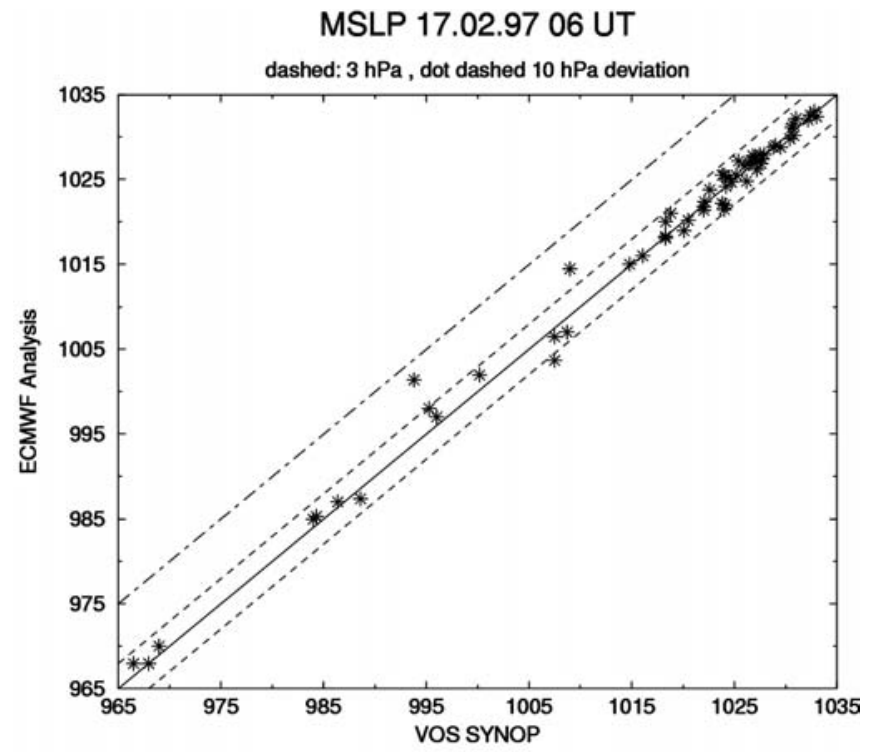

Figure 7: Comparison of MSLP VOS data and ECMWF analysis (AN) for 17 February 1997, 06 UTC. The dotted line indicates the allowed $3 \mathrm{hPa}$ error, the dot-dashed line indicates a $10 \mathrm{hPa}$ deviation.

were defined (Figure 3). Potential reasons for this underestimation are analyzed in section $4 \mathrm{c}$ and will be discussed in section 5 .

\subsection{Mean sea level pressure validation}

PFL precipitation in HOAPS and corresponding AVHRR cloud structures resemble distinct mesoscale cyclone features, that might be related to pressure anomalies. Therefore, the existence of such PFLs should be verifiable in the VOS surface pressure fields, resulting in a simple test of model quality. In contrast to the sparse rainfall observations, all of usually about 70 ships measure mean sea level pressure (MSLP) every six hours at the standard synoptic times, so that the observation density over the North Atlantic is fairly high. MSLP is a high quality PFL indicator, as the observations can be directly compared to the model output in contrast to the indirect estimate of precipitation from present weather. Another advantage of a MSLP comparison is, that it applies for a fixed time over the entire North Atlantic, in contrast to temporally varying overpasses of the satellites. The comparison uses the ECMWF FG data first, as this is the dataset that also contains the model precipitation data. In a second step, ECMWF improves FG data by recalculating it into the analysis data (AN) using VOS data. Then we test whether the ECMWF model is able to match the observed MSLP in more detail. At first, the ECMWF FG data is checked for MSLP anomalies compared to the VOS data. A deviation of $3 \mathrm{hPa}$, corresponding to a tolerable error in height difference of $24 \mathrm{~m}$, is allowed between both data sources to account for the smoothing of the NWP pressure field routines, slightly inaccurate observations or VOS measurements not properly reduced according to measurement height above sea level. Deviations above $3 \mathrm{hPa}$ are considered to be an anomaly. The data from the above mentioned ten case studies show, that nearly all data points match the $3 \mathrm{hPa}$ criterion well. Figure 4 shows the MSLP scatter plot for the discussed cyclone "Caroline" on 17 February 1997, 06 UTC, where $92 \%$ of all 72 MSLP ship measurements are within the $3 \mathrm{hPa}$ deviation. As expected, only few ships are cruising in regions of very low pressure. Obviously, there are six data points, for which the measured MSLP exceeds the tolerated deviation and four ships even reported a negative pressure anomaly of 4.1, 7.2, 8.5 and $10.4 \mathrm{hPa}$ if compared to ECMWF pressure. To further exclude errors in the ship data, the location of the ships showing the pressure anomalies are plotted. The black box plotted in Figure 5 shows, that all four VOS observations of anomalous low pressure are located in the area where the HOAPS data is showing the PFL precipitation. This leads to the conclusion that the precipitation in the ECMWF model could probably be missed because the mesoscale low-pressure system itself is not appropriately represented in the model. Ships in the vicinity of the PFL measured a cyclonic shift in the wind direction of about $50^{\circ}$ that might be also supported by scatterometer (NSCAT) satellite data. But as the resolution of the NSCAT data is too coarse and the number of VOS ships too low to proof a cyclonic mesoscale wind field with closed isobars further investigation is needed using high resolution ERS synthetic aperture radar data. The PFL precipitation occurs in the area of maximum horizontal SST gradients and maximum air sea temperature gradients of about $17^{\circ} \mathrm{C}$ as reported by VOS. The three hourly MSLP trend measured in the central region of the PFLs was about $-5 \mathrm{hPa} \mathrm{h}^{-1}$ whereas the pressure trend is positive in the vicinity of the PFL. The large pressure deviation near Florida is assumed to be a data error as surrounding pressure data cannot support this value and no significant cloud structures are found in the corresponding infrared AVHRR data.

All ten case studies with PFL precipitation in the HOAPS data and no corresponding precipitation in the ECMWF data show significant pressure differences in the PFL regions. The maximum pressure deviation between the VOS and the ECMWF data of $16 \mathrm{hPa}$ was found on 14 February 1997 (Figure 6c). On this day a tilt back occlusion of a mature low pressure system developed rapidly into a mesoscale PFL that exhibited intense convective precipitation in the HOAPS data. The region of the strongest pressure deviation coincides with the region of strongest PFL precipitation in the HOAPS data whereas the ECMWF model shows only minor amounts of precipitation (Figure $6 \mathrm{a}-\mathrm{b}$ ).

ECMWF operationally recalculates its FG product into an analysis product (AN). Over the ocean, this 


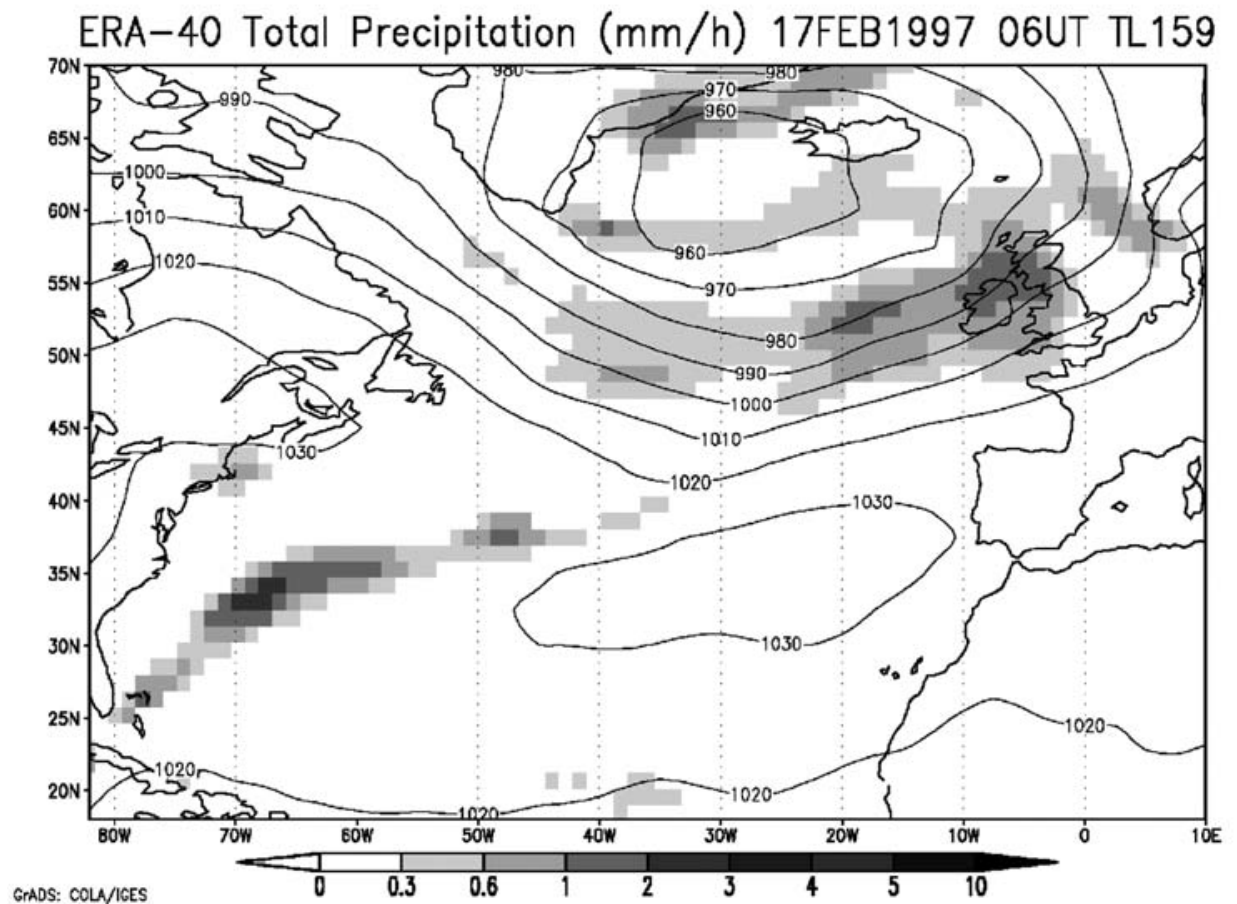

Figure 8: PFL case study from 17 February 1997 06UTC using ERA-40 total precipitation (mm/h) and surface pressure data (hPa). The rain rates within the PFL are between 0.3 and $1 \mathrm{~mm} / \mathrm{h}$. The maximum rain rate is $3 \mathrm{~mm} / \mathrm{h}$ within the cyclogenesis near the American coast.

PFL North Atlantic Precipitation

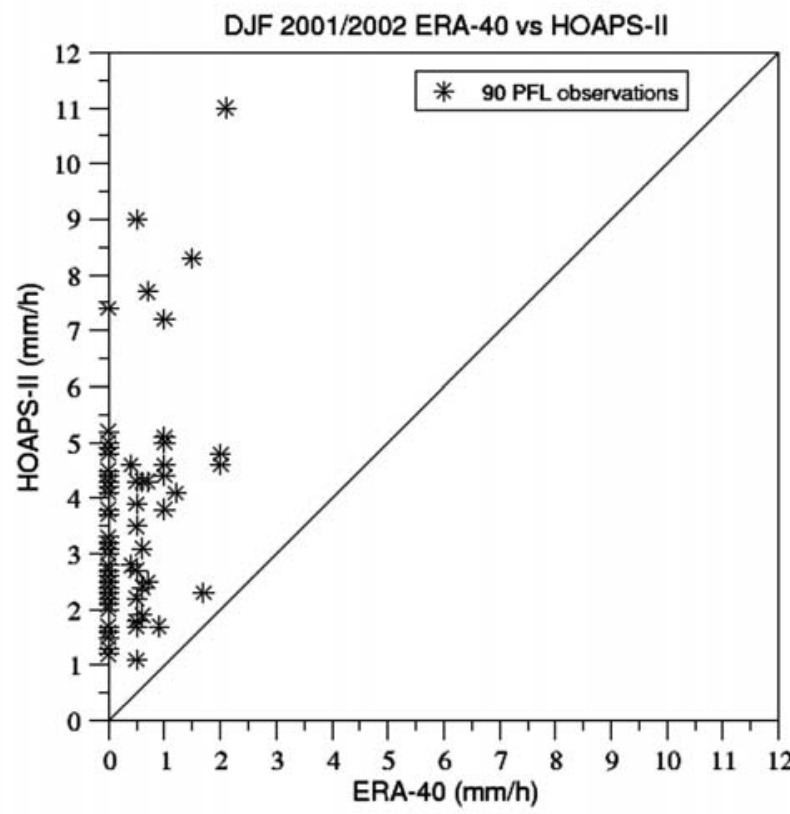

Figure 9: PFL precipitation comparisons between HOAPS and ERA-40 data for the winter 2001/2001 (1 December to 28 February).

dataset differs from the FG data as it allows the VOS data to correct the six hourly forecast. The analysis is only made for parameters that are directly measured, such as MSLP but not for precipitation. Therefore we expected that the ECMWF AN-data should be more realistic in reproducing the MSLP of the PFLs. Figure 7 shows the scatter plot and its corresponding MSLP array of the analysis data using the VOS data. As expected, the PFL pressure deviations between model and observation are now smaller but still exhibit a difference of 7.6 and $5.5 \mathrm{hPa}$.

Two model deficits were so far documented. At first, PFL precipitation observed by VOS and inferred by remote sensing (HOAPS) is mostly missing in the ECMWF model. Secondly, the PFLs themselves are not reproduced by the NWP model. Both deficits are strongly linked to each other, as the model cannot reproduce the precipitation without a corresponding lowpressure system causing it. This leads to the conclusion, that the question 'why is the PFL precipitation absent in the model?' should be replaced by the question 'why is the entire mesoscale low-pressure system not reproduced?' although VOS data are showing its existence.

\subsection{PFL representation in the ERA-40 data}

The case studies from 1997 were chosen due to the highly increased number of VOS observations during the FASTEX field campaign. This was necessary to obtain rainfall and surface pressure observations in usually very data sparse regions over the North Atlantic. The 1997 model system of ECMWF operated at that 
time was less sophisticated than it is these days. Therefore it becomes necessary to investigate if the underrepresentation of PFLs in the ECMWF is still valid in the more recent model version. Therefore we used ERA40 data in T159 resolution and re-investigated the case study from 17 February 1997. Figure 8 shows that, despite the coarser resolution, all precipitation features of the 1997 model version are well reproduced. While the shape of the PFL is well represented there is still a large underestimation of the precipitation rate. It is of major importance that the surface pressure field still exhibits a continuous flow from the Northwest without any representation of the PFL. To test if these findings are still valid in the more recent cases of the ERA-40 data base, a larger sample of data was used. Figure 9 shows a comparison between HOAPS and ERA-40 PFL precipitation data for the winter 2001 and 2002 from 1 December to 28 February. Again all fronts compared well between HOAPS and ERA-40. This data sample includes 180 case studies, i.e. twice daily data over the entire North Atlantic. 90 observations in the HOAPS data were found showing PFLs. On average each day in winter 2001/2002 showed a PFL. Many of these PFLs were stronger than the case study shown in Figure 2. In December 200114 mature low pressure systems formed with 7 PFLs that were active during 18 cases. In January 2002 there were 16 cyclones and 13 PFLs in 42 cases. In February 2002 the numbers lowered to 14 cyclones and 15 PFLs in 30 cases. It is evident from Figure 9 that the ERA-40 data base is vastly underestimating all PFL events. 58 out of 90 PFLs are absent in the model. 26 PFLs in the ERA data were below $1.1 \mathrm{~mm} / \mathrm{h}$, that is the lowest precipitation rate found in the HOAPS data. Only 3 cases in the ERA data reached rainfall up to 2 $\mathrm{mm} / \mathrm{h}$ while the corresponding maximum precipitation in the HOAS data reached $11 \mathrm{~mm} / \mathrm{h}$. These three cases are PFLs that resulted from occlusions which are tilted backwards, where the low pressure system still showed some connection to the PFL. This leads to the conclusion that, although we included more recent cases and applied the more sophisticated ERA-40 model system, the absence of PFLs still resemble the results obtained with the 1997 model version of ECMWF.

\section{Discussion and conclusions}

The comparison between HOAPS and the ECMWF model precipitation shows that PFLs are to a large extent suppressed within the model, whereas frontal precipitation fields compare well with the HOAPS data. The PFL patterns were neither reproduced by the model in any of the 10 case studies presented here nor in any other of several further case studies. Model data significantly underestimate PFL precipitation or show no rainfall at all. Even the use of the ECMWF ERA-40 reanalysis data for more recent case studies supports our findings. Only three out of 90 cases found in the ERA-40 data in winter 2001/2002 represented PFLs up to $2 \mathrm{~mm} / \mathrm{h}$ precipitation, compared to $11 \mathrm{~mm} / \mathrm{h}$ in HOAPS. This also supports our findings as these three cases belonged to PFLs that originated from tiltback occlusions. All three cases still showed a PFL low pressure connection to the mature cyclone to the Southeast. The surface pressure in the ERA-40 data is realistically low in these three PFL cases. This allows the model to produce precipitation.

To assess whether model grid resolution is a possible reason for underestimated or missed PFL precipitation in the ECMWF model, KEUP-THIEL et al. (2003) used the regional model REMO (JACOB, 2001) with a resolution of $1 / 6^{\circ}$ or $18 \mathrm{~km}$. With the much finer spatial resolution, REMO was run to give hourly precipitation output so that the temporal shift between the SSM/I overpasses and the REMO model output was minimized. The model was initialized with an ECMWF operational analysis at the lateral boundaries. If the spatial ECMWF model resolution of $0.5^{\circ}$ would be responsible for the discrepancies between the model and the satellite data the precipitation underestimation should be smaller in the REMO simulation. In contrast to this assumption, the REMO simulation also misses the PFL precipitation and mainly just resembles the ECMWF structures in greater detail. All REMO precipitation fields show the expected narrowing and more intense rainfall core structures compared to the 6-hourly integrals of the ECMWF model. REMO is neither producing additional rainfall areas nor forming own structures for the PFL rainfall area. The averaged PFL rainfall rate does not exceed $0.8 \mathrm{~mm} / \mathrm{h}$. All other investigated case studies show similar behavior of REMO in just reproducing the ECMWF structures in greater detail (KEUP-THIEL et al., 2003).

Another possible explanation of the missing model precipitation lies in the observed systematic MSLP differences between the VOS data and the ECMWF model. All investigated case studies had in common that the PFL areas tend to show significantly smaller MSLP in the observations than in the ECMWF model.

Such model behavior might have several reasons. The three hourly MSLP trend measured by VOS in the central region of the PFLs are about $-5 \mathrm{hPa} \mathrm{h}^{-1}$ whereas the pressure trend is positive in the vicinity of the mesoscale low. Usually there is only one VOS measurement, if any, centered in the area of the PFL due to the sparse observation density. On the one hand, it is possible that preprocessing model routines checking the input data for plausibility are rejecting observations with such large gradients or differences from the surroundings. On the other hand, it might be possible that such measurements are treated like a singularity in the initial MSLP fields and are therefore smoothed strongly by increasing the MSLP in the model. Additionally, the con- 
vection parameterization in the model is suspect to give not enough vertical mixing. The modeled postfrontal subsidence area is showing very small values of precipitable water and it extends to far into the area of the cold air outbreak in which the PFLs should form (BAUER, 2000).

In any case, the time series of the total amount of rainfall during the life cycle of North Atlantic cyclones points to the need to implement the PFLs properly into the models. Neglecting the equivalent of up to $1 \mathrm{~Sv}$ of PFL fresh water input into the oceans may lead to considerable errors in the modeled water cycle.

\section{Acknowledgements}

This study was funded by the Sonderforschungsbereich 512 (granted by the Deutsche Forschungsgemeinschaft to the University of Hamburg) and the Max-Planck Institut für Meteorologie, Hamburg, Germany.

\section{References}

BAuer, P., P. SCHLÜssel, 1993: Rainfall, total water, ice water and water vapor over sea from polarized microwave simulations and Special Sensor Microwave/Imager data. J. Geophys. Res. 98 (D11), 20737-20759.

BAUER, S., 2000: Validation of Clouds in the ECHAM4 Model Using a Dynamical Adjustment Technique. - MaxPlanck Institut for Meteorology, Hamburg, Germany, Examensarbeit, 143 pp. Obtainable from Max-Planck Institut für Meteorologie, Bundesstraße 53, 20146 Hamburg.

Ebert, E., A. MAnton, 1996: Results of the 3rd Algorithm Intercomparison Project (AIP-3) of the Global Precipitation Climatology Project (GPCP). Revision 1. - BMRC Research Report 55, 299 pp. Obtainable from Bureau of Meteorology, BMRC, PO Box 1289k, Melbourne, Australia.

ECMWF, 1994: User Guide to ECMWF products, Met. Bull. M3.2, Edition 2.0, 59 pp. Obtainable from ECMWF, Shinfield Park, Reading, RG2 9AX, UK.

FErraro, R., G. MARKS, 1995: The development of SSM/I rain rate retrieval algorithms using ground-based radar measurements. - J. Atmos. Ocean. Tech. 12, 755-770.

Grassl, H., V. Jost, J. Schulz, R. Kumar, P. BAuer, P. SCHLÜSSEL, 2000: A climatological atlas of satellitederived air-sea interaction parameters over the worlds ocean. - Max-Planck Report No. 312, 120 pp. Max-Planck Institute for Meteorology, Hamburg, Germany. obtainable from www.hoaps.org.

Huffman, G., R. Adler, P. Arkin, A. Chang, R. Ferraro, A. Gruber, J. Janowiak, A. McNab, B. Rudolf, U. SCHNEIDER, 1997: The Global Precipitation Climatology Project (GPCP) combined precipitation dataset. - Bull. Amer. Met. Soc. 78, 5-20.

IPCC (Intergovernmental Panel on Climate Change), 2001: Climate Change 2001: The Scientific Basis. Houghton et al. (Ed). - Cambridge University Press, Cambridge, UK, $881 \mathrm{pp}$.

JACOB, D., 2001: A note to the simulation of the annual and interannual variability of the water budget over the Baltic Sea drainage basin. - Meteor. Atmos. Phys. 77, 61-73.
Jost, V., 2000: HOAPS: Eine neue Klimatologie des Süßwasserflusses an der Meeresoberfläche abgeleitet aus Satellitendaten. - Dissertation, Universität Hamburg, 133 pp. Obtainable from Max-Planck Institut für Meteorologie, Bundesstraße 53, 20146 Hamburg.

Jost, V., S. BAKAn, K. FEnNig, 2002: HOAPS - A new Satellite-derived Freshwater Flux Climatology, - Meteorol. Z. 11, 61-70.

JoLY, A., 19 coauthors, 1997: Definition of the Fronts and Atlantic Storm-Track Experiment (FASTEX). - Bull. Amer. Met. Soc. 78, 1917-1940.

KeUp-Thiel, E., C. Klepp, E. RaschKe, B. Rockel, 2003: Regional model simulation of the North Atlantic cyclone "Caroline" and comparisons with satellite data. Ann. Geophys. 21, 655-659.

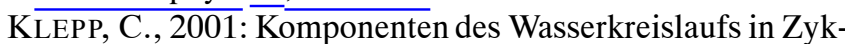
lonen aus Satellitendaten-Niederschlagsfallstudien. - MaxPlanck Institut for Meteorology, Hamburg, Germany, ISSN 0938-5177, Examensarbeit Nr. 82, 161 pp. Obtainable from Max-Planck Institut für Meteorologie, Bundesstraße 53, 20146 Hamburg.

KlepP, C., S. BAKAN, 2000: Satellite derived energy and water cycle components in North Atlantic cyclones. -Phys. Chem. Earth (B) 25, 65-68.

KLEPP, C., S. BAKAN, H. GRASSL, 2003: Improvements of satellite derived cyclonic rainfall over the North Atlantic.J. Climate 16, 657-669.

KLEPP, C., K. FENNIG, S. BAKAN, H. GRASSL, 2005: HOAPS-II Global Ocean Precipitation Data Base. - Eumetsat Proceedings, P. 44, Second International Precipitation Working Group Workshop, ISBN 92-9110-070-6, 169-176. Obtainable from www.isac.cnr.it/ ipwg/meetings/monterey/pdf/Klepp.pdf.

Kummerow, C., W.S. Olson, L. Giglio, 1996: A simplified scheme for obtaining precipitation and vertical hydrometeor profiles from passive microwave sensors. - IEEE Trans. Geosci. Remote Sens. 34, 1213-1232.

Kummerow, C., Y. Hong, W.S. Olson, S. Yang, R.F. Adler, J. McCollum, R. Ferraro, G. Petty, D.-B. Shin, T.T. Wilheit, 2001: The Evolution of the Goddard Profiling Algorithm (GPROF) for Rainfall Estimation from Passive Microwave Sensors. - J. Appl. Meteor. 40, 18011820.

Smith, E., 25 coauthors, 1998: Results of the WetNet PIP-2. - J. Atmos Sci. 55, 1483-1536.

Susskind, J., P. Piraino, L. Rokke, L. Iredell, A. MEHTA, 1997: Characteristics of the TOVS Pathfinder Path A Dataset. - Bull. Amer. Meteor. Soc. 78, 1449-1472.

WENTZ, F., 1991: User's manual SSM/I antenna temperature geophysical tapes. - Technical Report 120191, Remote Sensing Systems, Santa Rosa, California. Obtainable from Remote Sensing Systems, 438 First Street, Suite 200, Santa Rosa, CA95401, USA.

WENTZ, F., 1997: A well-calibrated ocean algorithm for special sensor microwave/imager. - J. Geophys. Res. 102 (C4), 8703-8718.

WILLIAMS, K.D., 2000: Mesoscale analysis of a comma cloud observed during FASTEX. - Meteor. Appl. 7, 129_ 134. 